\title{
SINDROME DE PYLE COM FRAGMENTAÇÃO CROMOSSÔMICA
}

\author{
Aron J. Diament * \\ Anita Wajntal ** \\ P. H. Saldanha ***
}

As displasias metafisárias familiares são moléstias raras. A primeira descrição coube a Hamann (cit. por Becker ${ }^{3}$ ), como achado necroscópico; a propósito assinalou aquele autor uma observação de Jones, um ano antes, sôbre um esqueleto achado nas escavações de uma necrópole núbica, o qual apresentava engrossamento do têrço distal do fêmur e proximal da tíbia, além de encurvamento em $\mathrm{S}$ itálico da diáfise tibial. Em 1931, Pyle ${ }^{16}$ desconhecendo o trabalho de Hamann publicou o caso de uma criança de 5 anos de idade, do sexo feminino, que apresentava engrossamento das extremidades ósseas dos membros e um crânio deformado, isto é, com a região frontal proeminente. A criança era psiquicamente normal. Para explicar as hipertrofias ósseas em forma de taça Pyle invocou uma falha na reabsorção de certas partes ósseas (da cortical metafisária, desde a cavidade medular), em resposta ao crescimento longitudinal do osso diafisário. Bakwin e Krida (cit. por Becker ${ }^{3}$ ) examinaram a criança que Pyle descreveu e também sua irmã, de 7 anos de idade, apresentando deformações semelhantes.

Até 1960 haviam sido descritos $22 \operatorname{casos}^{19}$. Becker ${ }^{3}$, até 1966, refere 35 casos reconhecidos como sindrome de Pyle, sendo apenas 17 com atingimento craniano, de tipo leontíase óssea. Jackson e col. propuseram o nome de displasia crânio-metafisária para êstes casos.

As displasias metafisárias são transmitidas de forma dominante em alguns casos, e de forma recessiva, em outros ${ }^{3,9,12}$. Alguns casos foram errôneamente diagnosticados como osteopetrose ou leontíase óssea, em vista das alterações radiológicas cranianas ${ }^{19}$. Mitchel e Mac Leod (cit. por Jackson e col. ${ }^{9}$ ) sugeriram, em seu caso, uma ligação entre osteopetrose e displasia metafisária, ambas com idênticas alterações metafisárias. Entretanto, para Jackson e col. ${ }^{y}$ haveria uma diferença: enquanto na osteopetrose a anomalia fundamental seria uma inabilidade em reabsorver ossos, na displasia metafisária o esqueleto todo responderia, em certo grau, aos "stresses" normais e esforços no trabalho, sòmente a cortical falhando em ser remodelada. Aqui, o defeito seria local e, na osteopetrose, geral. Porém, os resultados finais

* Assistente da Clinica Neurológica da Faculdade de Medicina da Universidade de Sāo Paulo; ** Instrutor e *** Professor de Disciplina de Genética Humana e Chefe do Laboratório de Genética Médica, da Faculdade de Medicina da Universidade de sāo paulo. 
seriam comparáveis nas duas entidades. Jackson e col. ${ }^{9}$ apresentam sugestivas relações entre aquelas duas entidades e várias subvariedades.

A histopatologia do processo que leva à displasia crânio-metafisária (DCM) é pouco conhecida. Estudos com radioisótopos (estrôncio ${ }^{85}$ ) revelaram a presença de grande quantidade de osteóides, com grande demanda de cálcio ${ }^{19}$. Halliday (cit. por Schwarz ${ }^{19}$ ) refere o mesmo quanto ao cálcio. O distúrbio geral do metabolismo do cálcio explicaria, em alguns casos, o achado de osteomalácia. Mas, conclui Schwarz, são necessários estudos mais aprofundados sôbre o metabolismo do cálcio.

Os achados anátomo-pa'ológicos nas displasias familiares mostram formação exagerada de osso subperióstico. A cervical externa, correspondente aos segmentos engrossados das extremidades ósseas inferiores e superiores, aparece notadamente adelgaçada. A cavidade medular está reduzida, como resultado da hiperatividade osteoblástica nos condutos de Havers, contrastando com a grande expansão da esponjosa (Ingalls, cit. por Becker ${ }^{3}$ e Jackson e col. ${ }^{9}$ ). Em alguns pacientes, na forma crânio-metafisária, existem também lesões dos ossos chatos do crânio, na forma de hiperostose mais ou menos extensa da abóboda ou nos ossos do maciço facial, revestindo a imagem de leontíase óssea. Nesta última localização os seios paranasais quase sempre se ossificam, assim como a apófise mastóidea, levando em certos casos à hipoacusia e amaurose ${ }^{3}$.

A sintomatologia neurológica nos casos de DCM é variável, geralmente pobre, dependenđò da extensão e intensidade do envolvimento do crânio pela deformidade óssea. Em casos atípicos as manifestações são mínimas ou ausentes (Ellis; Feld, Switzer, Dexter e Langer, todos citados por Schwarz ${ }^{19}$ ). Mori e Holt (cit. por Schwarz ${ }^{19}$ ) referem hipertelorismo e anormalidades dos nervos cranianos, com perda da audição e visão. Embora êstes autores não refiram deficiência mental (DM), Jackson e col. ${ }^{9}$ citam-na num caso de um menino de 15 anos de idade, além de amaurose. Klintworth ${ }^{12}$ achou em alguns casos tão severo o comprometimento cerebral, que considerou a DCM uma variante da osteopetrose, na qual são descritas alterações com mais gravidade.

Recentemente, Roy e col. ${ }^{17}$ relataram um caso semelhante à síndrome de Pyle, corém apresentando uma síndrome cutânea (anetodermia) e graves perturbações neuropsíquicas. Não encontraram alterações cromossômicas e fazem correlação desta síndrome ósteo-neurocutânea com as neurectodermoses.

Nosso propósito é relatar um caso que se aproxima, sob o aspecto radiológico, da síndrome de Pyle, mas com graves alterações neuropsíquicas progressivas e, no qual, foi encontrada uma aberração cromossômica.

O B S E R V A C A O

V.F.R., 3 anos e 6 meses de idade, sexo feminino, atendida no ambulatório de Neuropediatria em 14-10-1964 (RG: 727085). Foi trazida à consulta por apresentar retardo neuropsicomotor ( não anda, não fala e não entende bem as coisas) além de estar quase sempre agitada e excitada, mordendo-se; quase não dorme. Antecedentes 
- Trata-se da segunda filha da 2. gestação, que foi normal; parto a têrmo, mediante cesária por distócia de bacia na mãe. Não houve cianose perinatal e a criança chorou pouco e fracamente ao nascer. Sucçao normal. Não houve icterícia neonatal. Sustentou a cabeça com quase dois anos. Sentou com 2 anos e 8 meses. Fica de pé apoiada e troca alguns passos apoiada. Aos 7 meses de idade começou a ter convulsōes, tipo GM atônico, com duração de 5 minutos; mais tarde os ataques passaram a ser como um "choque", em que os membros se estendiam, com duraçāo de segundos, na freqüência de 2 a 3 por dia; tais crises cessaram um ano após o inicio. Caxumba com 2 anos e 3 meses. Pais consangüíneos, primos em $3 .^{\circ}$ grau duplo ( $\mathrm{f}=1 / 13$, Graf. 1). Uma irmã normal com 8 anos de idade. Um irmāo do pai, com 35 anos, casado com pessoa não aparentada, tem uma prole de 9 filhos, dos quais 2 faleceram no primeiro mês de vida (respectivamente, um de cada sexo), de causa nāo esclarecida e os 7 restantes são vivos, sendo que um teve febre e ataques aos 3 meses de vida e dois têm atraso mental, mas com caracteristicas aparentemente diferentes das descritas para a paciente. Ambos os pais são obesos e o pai tem extremidades grossas. Ea:ame físico geral e especial nada digno de nota. Exame neurológico - Perimetro craniano de $52 \mathrm{~cm}$, som timpánico à percussão, tendendo a maciço. A paciente não contactua pela visão, audição, fala e mímica. Lalação presente. Atitude em decúbito dorsal horizontal ou sentada. Fica de pé sem apôio, sentando com ou sem apôio. Não existem déficits aparentes. Praxias de defesa presentes. Tono muscular normal. Dos reflexos miotáticos só foram obtidos os patelares e o nasopalpebral, simétricos. A paciente não segue foco luminoso e não tem reflexos fotomotores. Eletrencefalograma, em 2-12-1964, normal.

Evolução - Em novembro de 1964 a paciente teve sarampo e piorou do estado geral e neuropsicomotor, tendo sido receitado Anatensol e Gabalon. Desde então, voltou à consulta sòmente em 28-8-1968. Com 5 anos e meio, segundo a mãe, chegou a dar alguns passos sòzinha. Pronunciava algumas palavras, como "papa", "titia", "água", "babo", "nana", "deda". Com 6 anos de idade teve uma convulsão GM, generalizada, com duração de meia hora; 4 a 5 dias após já se levantava menos e, desde entāo, foi perdendo paulatinamente as habilidades adquiridas. Está atualmente com 7 anos e meio e, em 15 dias, após aquela convulsão, sofreu involução psicomotora total. Segundo a mãe escuta mas, não atende a ordens (sic); ri e procura algo quando se pronuncia a palavra papai (sic). Exames clínicos geral e especial nada digno de nota, afora sinais de puberdade precoce. Exame neurológico - Perímetro craniano de $53 \mathrm{~cm}$. Tetraplegia espástica desproporcionada, predominando nos membros direitos; alguns movimentos no membro inferior esquerdo. Hipertonia dos flexores dos membros superiores e extensores dos inferiores; nestes, mais intensa no direito, que fica em permanente hiperextensão. Retraçōes dos tendôes de Aquiles, maior à direita (Fig. 1, A e B). Dificuldade em mastigar e deglutir. Hiperreflexia profunda generalizada. Reflexos cutâneo-abdominais presentes, somente com resposta superior, mais evidente à direita; nos pés, sinal de Babinski e leque bilaterais; Rossolimo e Mendel-Bechterew presentes, bilateralmente. Pés rodados para dentro e hiperestendidos, mais à direita. Sensibilidade dolorosa aparentemente presente. Pupilas midriáticas e simétricas, nāo reagindo à luz. Fundos oculares: papilas aumentadas de diâmetro em $\mathrm{AO}$, sem elevação de nivel, com bordos nitidos e coloração esbranquiçada, grande escavação fisiológica; retina e vasos normais; êste exame sugere haver atrofia simples das papilas, em que pese a dificuldade do exame pela alta miopia (fundus visivel com $25 \mathrm{DE}$ ). Eletrencefalograma, em 29-8-1968: lento e desorganizado para a idade, mostrando sinais de atividade irritativa, oastante intensa, de projeção predominante na região occipital direita (surtos reiterados de ondas "sharp" lentas). Consulta endocrinológica A idade óssea, pelas radiografias das māos é de 6 anos e meio (normal para a idade cronológica). Sinais de puberdade precoce; a penugem pubiana nāo se acompanha de aumento de clítoris (Fig. 1. C) nem de mamoplasia. Exames radiológicos, em 1-3-1967 - Ossos longos com alargamento das metáfises, particularmente nas extremidades distais dos fêmures (Fig. 1, D e E). Esta deformidade foi também assinalada nas extremidades esternais das claviculas. No ossos tubulares curtos, alargamento moderado das metáfises dos metacarpianos, metatarsianos e falanges; 

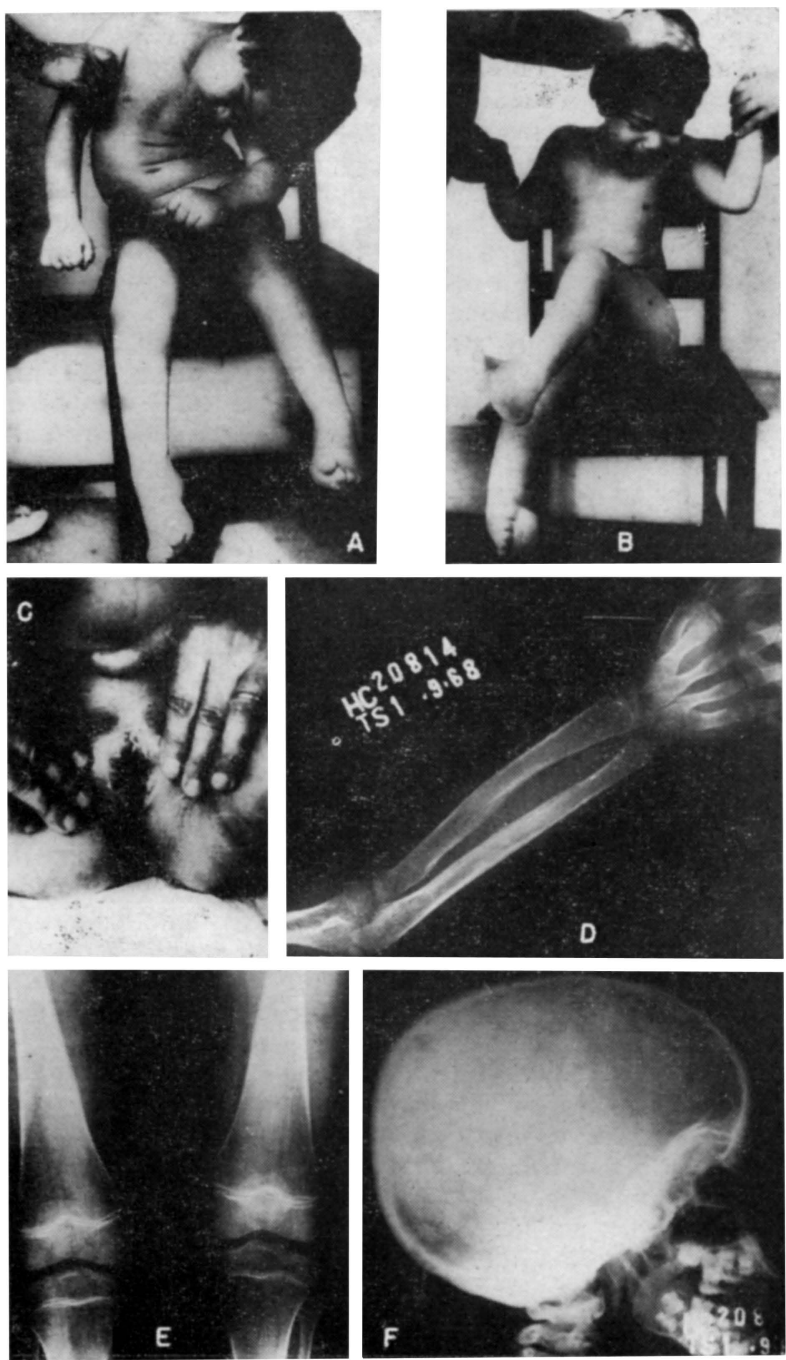

Fig. 1 - Caso V.F.R.. Em A, atitude geral da criança mostrando torsão tóraco-lombar, flexão dos dedos das mãos e hiperextensão dos pés. $\operatorname{Em} B$, atitude da criança quando se tentou retificar o desvio da coluna vertebral. Em $C$, genitais a paciente aos 7 anos de idade, mostrando puberdade precoce (penugem, sem aumento do clitoris). Em $D$, radiografias do rádio e cúbito mostrando o aspecto caracteristico em taça, por alargamento das metáfises. Em E, radiografia da região do joelho mostrando o alargamento das metáfises, principalmente no fêmur. Em $F$, radiografia do crànio mostrando esclerose ebúrnea na base. 
as corticais são bastante adelgaçadas nas áreas metafisárias; as porcōes médio-diafisárias apresentam forma, diâmetro e corticais no limite do normal, exceto nos úmeros, onde o alongamento se estende até os têrços distais das diáfises. Idade óssea média: os núcleos apresentam um gráu médio de maturidade ao redor de 6 anos e meio; o pisiforme corresponde a uma idade óssea de 9 anos e 6 meses. No crânio, esclerose ebúrnea (Fig. 1, F) particularmente das grandes asas do esfenóide e das porções petrosas de ambos os temporais; não há distúrbio da aeração dos seios frontais e maxilares; seios esfenóides eburnizados; sela túrcica pequena, com esclerose das clinóides anteriores e tubérculo médio. Na coluna vertebral, exceto no atlas que apresenta uma esclerose semelhante à base do crânio, não existem alterações significativas. Nos ossos chatos, aumento moderado de densidade da textura óssea, particularmente nas porções basais dos iliacos, onde se observam placas de esclerose ebúrnea. Em conclusāo, os exames radiológicos sugerem quadro de displasia crânio-metafisária, tarda (síndrome de Pyle). Cálcio sérico $11,5 \mathrm{mg} \%$. Fósforo inorgânico $6 \mathrm{mg} \%$. Fosfatose alcalina 6 unidades King-Armstrong. Novos exames radiográficos de ossos, em 3-9-1968 - A esclerose da base do crânio acentuou-se, com restrição progressiva da sela túrcica; verifica-e, agora, certo grau de osteoporose difusa, espessamento da cortical dos ossos do antebraço e, também, o aparecimento de pequeras exosteses nas tíbias. Exame citogenético e dermatoglífico - $O$ estudo do cariótipo em cultura de sangue periférico revelou mosaicismo, com presença de um fragmento em cêrca de $12 \%$ das mitoses estudadas na paciente (Figs. 2 e 3). O estudo do cariótipo da irmã e do contrôle submetido ả mesma medicaçāo que o propósito (hidantoinatos), não revelou alterações (Tabela 1). O sexo nuclear do propósito (mucosa oral) foi feminino normal com $19 \%$ das células com cromatina sexual. Os dermatoglifos do propósito, seus pais e da irmã normal estão descritos na tabela 2 .

\section{O M E N T A R I O S}

O caso descrito apresenta uma sindrome óssea e uma sindrome neuropsíquica. A síndrome óssea se caracteriza por esclerose da base do crânio, alargamento das metáfises dos ossos longos e placas de esclerose ebúrnea nos ossos chatos, caracterizando o quadro das displasias crânio-metafisárias. A síndrome neuropsíquica se caracteriza por atraso neuropsicomotor, síndrome convulsiva GM, síndrome pirâmido-extrapiramidal com tetraplegia espástica. A não contactuação pela audição e visão poderia ser explicada por acometimento dos nervos cranianos pelo espessamento da base do crânio. Porém, tal espessamento não é suficiente para explicar todo o quadro neurológico da paciente. Parece ter havido estreita relação entre o reinicio das crises convulsivas e a ulterior involução psicomotora, embora a criança já apresentasse retardo, tendo chegado a andar e a falar umas poucas palavras; após as crises houve involução total. Os sinais pirâmido-extrapiramidais também surgiram após as crises convulsivas. Neste caso o número e a intensidade das crises foi insuficiente para explicar o quadro como conseqüência pós-convulsiva de etiopatogenia vascular (anóxia).

O quadro ósseo da paciente é de DCM ou síndrome de Pyle. O quadro neuropsíquico se aproxima do descrito por Roy e col. ${ }^{17}$; falta, porém, a síndrome cutânea de anetodermia para uma identidade entre os dois casos. Além do mais, o encontro de ưma aberração cromossômica torna o problema mais complicado. 


\begin{tabular}{|c|c|c|c|c|c|c|c|}
\hline \multirow[b]{2}{*}{$\begin{array}{l}\text { Média de } \\
\text { exames }\end{array}$} & \multicolumn{6}{|c|}{ Número de cromossomos } & \multirow[b]{2}{*}{ Total } \\
\hline & 43 & 44 & 45 & 46 & 47 & 48 & \\
\hline & 1. ${ }^{\text {. }}$ cultura & 0 & 0 & 15 & $3 *$ & 0 & 18 \\
\hline Propósito & 2. cultura & 0 & 1 & 19 & $2^{*}$ & 0 & 22 \\
\hline Total & & 0 & 1 & 34 & 5 & 0 & 40 \\
\hline Irmã & & 1 & 1 & 38 & 0 & 0 & 40 \\
\hline Contrôle & 1 & 0 & 1 & 38 & 0 & 0 & 40 \\
\hline
\end{tabular}

Tabela 1 - Distribuição dos cromossomos por mitoses do propósito, de sua irmã e de um contrôle. " cromossomo extra-fragmentado.

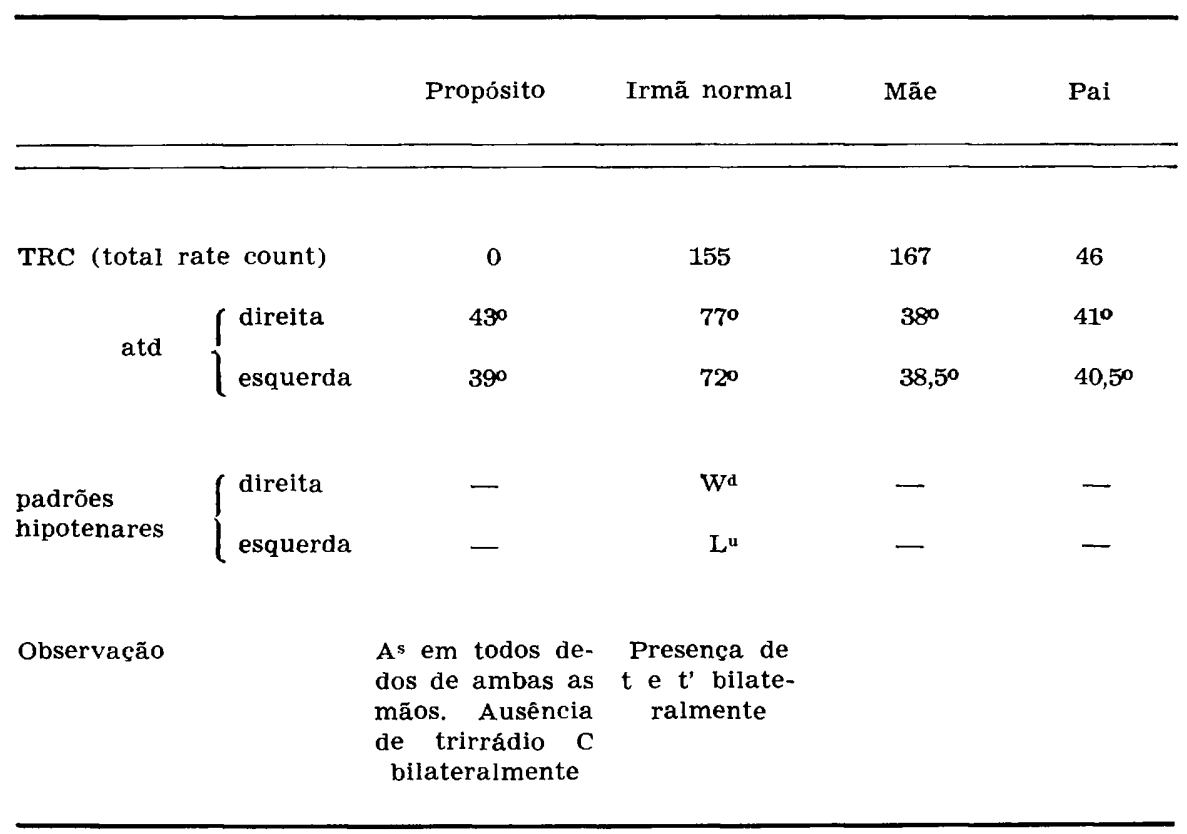


O exame da genealogia (Gráfico 1) evidencia que o propósito é o único afetado de uma irmandade de dois indivíduos. Os pais do propósito são normais e a anomalia não aparece em qualquer membro de outra geração. Essas observações e o fato dos pais do propósito serem primos em $3 .^{\circ}$ grau múltiplo ( $f=1 / 13$ ) sugerem que a anomalia tenha um tipo de herança recessiva. Todavia, o presente caso, além da aparente etiologia gênica, envolve alterações cromossômicas, já que $12 \%$ das mitoses do propósito apresentam um fragmento.

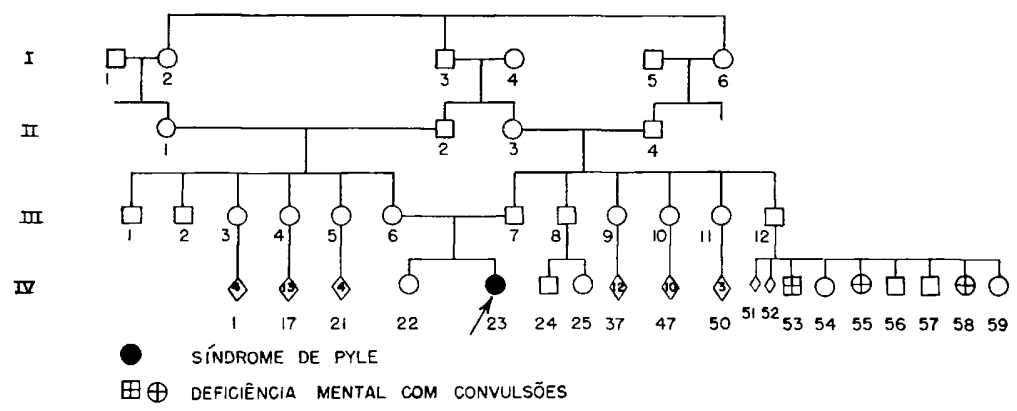

Gráfico 1 - Genealogia do propósito.

Uma freqüência aumentada de quebras cromossômicas tem sido observada em algumas anomalias hereditárias recessivas: sindrome de Bloom (German e col. ${ }^{6}$ ), anemia de Fancomi (Bloom e col. ${ }^{4}$ ), ataxia-telangiectasia (Hecht e col. ${ }^{8}$ ), agamaglobulinemia (Jacobs e col. ${ }^{10}$ ), síndrome de Cornelia de Lange (Jervis e Stimson ${ }^{11}$ ) e na anemia megaloblástica (Botura e Coutinho ${ }^{5}$ ). Schuler e col. ${ }^{18}$ encontraram uma suscetibilidade aumentada dos cromossomos de pacientes com anemia de Fanconi, quando em presença de alquilantes. Estes autores sugerem que êste aumento de suscetibilidade reflete uma estrutura alterada, em pacientes com esta anomalia. Diversos mecanismos têm sido sugeridos para explicar essa associação. Alguns acreditam numa suscetibilidade aumentada a infecções por vírus tais como os do sarampo (Nichols e col. ${ }^{13}$; Nichols ${ }^{15}$ ), da varicela (Aula ${ }^{2}$ ), do herpes simples (Stich e col. ${ }^{20}$ ) e da febre amarela (Harnden ${ }^{7}$ ), que aumentariam a freqüència de quebras in vivo e in vitro. Estes vírus poderiam agir tanto diretamente sôbre os cromossomos, como indiretamente, por mecanismo tóxico ou imunológico ( $\mathrm{Ni}$ chols ${ }^{14}$ ). Por outro lado, Allison e Patton ${ }^{1}$ demonstraram que a ativação de enzimas lisossômicos era responsável por um aumento de quebras nos cromossomos. Portanto, qualquer mecanismo de liberação dêstes enzimas ou aumento de sua produção poderia, como conseqüência, produzir um número aumentado de fragmentos cromossômicos. Uma outra possibilidade etiológica de quebra cromossômica seria um mecanismo de reparo dos cromossomos, como resultado do metabolismo oxidativo, com formação de ATP (Wolff e Luitpold ${ }^{21}$ ). A alteração dêste metabolismo, impedindo a regeneração normal do material genético, poderia ser outra causa da freqüência aumentada 
de fragmentos em anomalias de herança recessiva. Entretanto, em nosso caso, a variabilidade no tamanho dos fragmentos cromossômicos (Figs. 2 e 3) sugere que a fragmentação seja realmente por efeito secundário.

R E S U M O

E relatado o caso de uma paciente com sindrome de Pyle (displasia crâniometafisária), com sintomatologia de involução neuropsiquica progressiva e sinais pirâmido-extrapiramidais. O estudo do cariótipo revelou a presença, em $12 \%$ das células, de fragmentação cromossômica, embora a análise da genealogia do propósito revelasse tratar-se de provável moléstia recessiva. São discutidas as hipóteses dos mecanismos da fragmentação cromossômica em tais eventualidades (moléstias recessivas), concluindo-se por provável fragmentação secundária no caso em questão.

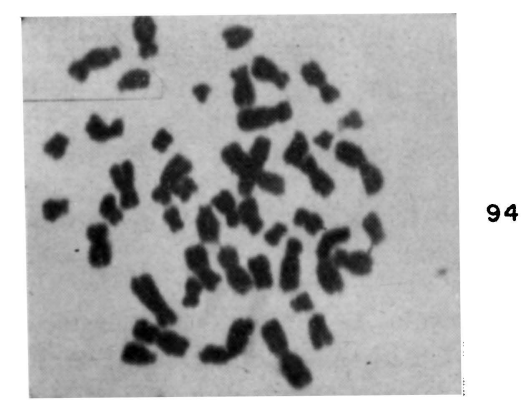

\section{if $18 \int_{3}^{81} \quad 1311$

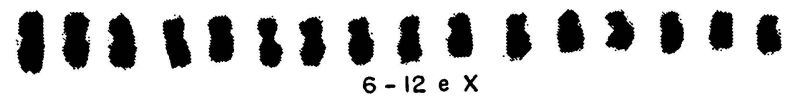

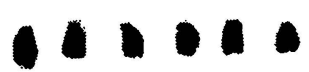

$13-15$

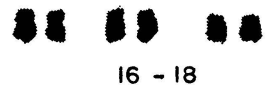

$16-18$

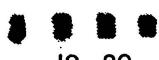

$19-20$

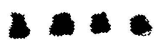

21 -22

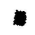

frag.

Fig. 2 - Cariótipo do propósito mostrando fragmento pequeno. 


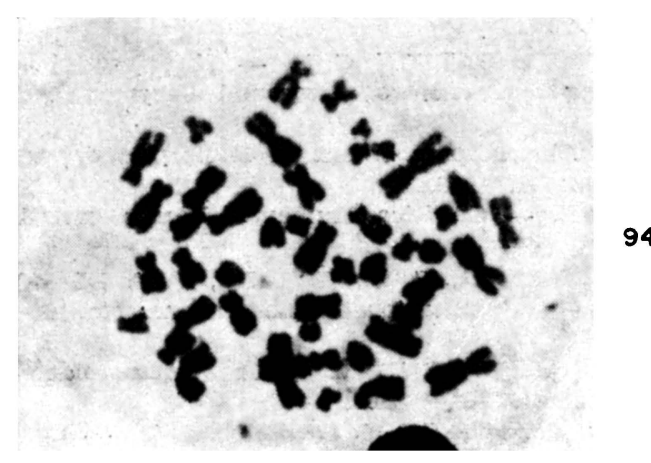

94

\section{$16818 \times$ \\ 123

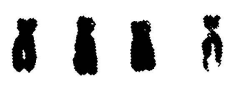 \\ 4-5 \\ $2108888 \times 808868 \times$ \\ $6-12 \cdot x$}

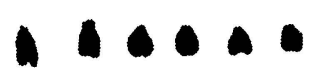

$13-15$

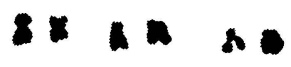

$16-18$
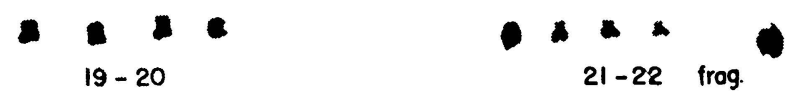

Fig. 3 - Cariótipo do propósito mostrando fragmento grande.

Pyle's syndrome and chromosomal breakage: a case report

The clinical and karyotypic analysis of a 7 years old girl with Pyle's disease are reported. Clinically the patient presented an unusual neuropsychic involution and pyramido-extrapyramidal symptomatology. The karyotypic analysis showed chromosomal breakage em $12 \%$ of the cells. However the genealogical study of the patient pointed towards a recessive disease. Various hypothesis of chromosomal breakage in recessive diseases are discussed, the possibility of secondary breakage being emphasized. 


\section{R E F E R N C I A S}

1. Allison, A. C. \& PATTON, G. R. - Chromosomes damage in human diploid cells following activation of lysosomal enzymes. Nature (London) 207:1170, 1965.

2. AULA, P. - Chromosome breaks in leukocytes of chikenpox patients. Hereditas (Lund) 43:451, 1963.

3. BECKER, P. E. - Genética Humana. Versão castelhana. Ed. Toray, Barcelona, 1966. pp. 40-41.

4. BLOOM, D.; WARNER, G. S.; GERALD, P. \& DIAMOND, L. - Chromosomes abnormalities in constitutional aplastic anaemia. New Engl. J. Med. 274:8, 1966.

5. BOTTURA, C. \& COUTINHO, V. - The chromosome anomalies of the megaloblastic anaemias. Blut 16:193, 1968.

6. GERMAN, J.; ARCHIBALD, R. \& BLOOM, D. - Chromosomal breakage in a rare and probably genetically determined syndrome of man. Science 148:506, 1965.

7. HARNDEN, D. G. - Cytogenetic studies on patients with virus infections and subjects vaccinated against yellow fever. Amer. J, Hum Genet. 16:204, 1964.

8. HECHT, F.; KOLER, R. D.; RIGAS, D. A.; DAHNKE, G. S.; CASE, N. P.; TISDALE, V. \& MILLER, R. W. - Leukaemia and lymphocytes in telangiectasia. Lancet $2: 1193,1966$.

9. JACKSON, W. P. U.; ALBRIGHT, F.; DREWRY, G.; HANELIN, J. \& RUBIN, M. I. - Metaphyseal dysplasia, epiphyseal dysplasia, diaphyseal dysplasia and related conditions. I. Familial metaphyseal and cranimetaphyseal dysplasia; their relation to leontiasis ossea and osteopetrosis; disorder of "bone remodeling". Arch. int. Med. 94:871, 1954.

10. JACOBS, J. C.; BLANC, W. A.; CAPOA, A. de; HEIRD, W. C.; McGILVRAY, E.; MILLER, O. J.; MORSE, J. H.; ROSSEN, R. D.; SCHULLINGER, J. N. \& WALTTZER, R. A. - Complement deficiency and chromosomal breaks in a case of a swiss type agammaglobulinaemia. Lancet 1:499, 1968.

11. JERVIS, G. A. \& STIMSON, C. W. - De Lange syndrome - the "Amsterdam type" of mental defect with congenital malformation. J. Pediat. 63:634, 1963.

12. KLINTWORTH, G. K. - The neurologic manifestations of osteopetrosis (Albers Schönberg's disease). Neurology (Minneapolis) 13:512, 1963.

13. NICHOLS, W. W.; LEVAN, A.; HALL, B. \& OSTERGREN, G. - Measles associated chromosome breakage. Hereditas (Lund) 48:367, 1962.

14. NICHOLS, W. W. - Relationships of viruses, chromosomes and carcinogenesis. Hereditas (Lund) 50:53, 1963.

15. NICHOLS, W. W. - The role of viruses in the etiology of chromosomal abnormalities. Amer. J. Hum. Genet. 18:81, 1966.

16. PYLE, E. - A case of unusual bone development., J. Bone Jt. Surg. 13:874, 1931.

17. ROY, C.; MAROTEAUX, P.; KREMP, L.; COURTECUISSE, V. \& LAGILLE, D. - Un nouveau syndrome osseux avec anomalies cutanées et troubles neurologiques. Arch. franc. Pédiat. 25:893, 1968.

18. SCHULER, D.; KISS, A. \& FABIAN, F. - Chromosomal peculiarities and "in vitro" examinations in Franconi's anaemia. Humangenetik 7:314, 1969.

19. SCHWARZ, E. - Craniometaphyseal dysplasia. Amer. J. Roentgenol 84:461, 1960.

30, STICH, H. F.; HSU, T. C. \& RAPP, F. - Viruses and mammalian chromosomes. Localization of chromosome aberrations after infection with herpes simplex virus. Virulogy $22: 439,1964$.

21. WOLFF, S. \& LUIPPOLD, H. E. - Metabolism and chromose breakage rejoining. Science 122:231, 1955.

Clinica Neurológica - Faculdade de Medicina, Universidade de São Paulo Caixa Postal $\$ 461$ - São Paulo, SP - Brasil. 